\title{
Estudo das propriedades mecânicas dos tubos de papelão visando sua utilização no design de produtos
}

Study of the mechanical properties of cardboard tubes for their use in product design

PICCOLI, Mariana; Mestra em Design; IF Sul Rio-grandense

marianap.piccoli@gmail.com

PACHECO, Joyson. Doutor em Engenharia Metalúrgica; Universidade Federal do Rio Grande do Sul joyson@mecanica.ufrgs.br

BRANDI, Leonardo Barili; Mestre em Design; Pontifícia Universidade Católica do Rio Grande do Sul leonardo.barili@gmail.com

\section{Resumo}

Este trabalho teve como objetivo identificar os parâmetros técnicos de resistência de tubos de papelão quando submetidos a esforços de compressão, visando gerar informações que estimulem a utilização deste material no design de produtos. Foram realizados ensaios técnicos de resistência à compressão axial e diametral. Pelos resultados, concluiu-se que a direção mais adequada e com maior relevância de utilização dos tubos de papelão é a vertical, com o sentido da carga aplicado paralelamente à seção transversal. As falhas apresentadas não são repentinas; as amostras permanecem estáveis, já que não houve ruptura súbita. Assim, concluiu-se que o tubo de papelão é um material passível de aplicação no design de produtos, em condições onde a resistência à compressão é um requisito. Por fim, acredita-se que o estudo e reconhecimento de características peculiares de novos materiais é um ponto determinante para a inserção destes no Design.

Palavras Chave: tubos de papelão; parâmetros técnicos; propriedades mecânicas; design de produto.

\begin{abstract}
The objective of this work was to identify the technical parameters of resistance of cardboard tubes when subjected to compression efforts, in order to generate information that stimulate the use of this material in product design. Technical tests of resistance to axial and diametral compression were carried out. From the results, it was concluded that the most suitable and most relevant direction of use of the cardboard tubes is vertical, with the direction of the load applied parallel to the cross section. The failures presented are not sudden; the samples remain stable, since there was no sudden rupture. Thus, it has been found that the paperboard tube is a material suitable for application in product design, under conditions where the compressive strength is a requirement. Finally, it is believed that the study and recognition of peculiar characteristics of new materials is a determining point for the insertion of these in Design field.
\end{abstract}

Keywords: cardboard tubes; technical parameters; mechanical properties; product design. 


\section{Introdução}

Os tubos de papelão são utilizados em diversos segmentos industriais - seja na forma de embalagem ou como suporte para o enrolamento de tecido, papéis, polímeros, adesivos e outros tipos de películas e fios. É um material muito utilizado para armazenagem e transporte de mercadorias por sua versatilidade e baixo custo, podendo ser fabricado em diversos comprimentos, diâmetros e espessuras. Além disso, os tubos de papelão apresentam vários critérios ecológicos no seu ciclo de vida (desde a fabricação ao descarte), tornando-se um material com baixo impacto ambiental e indo ao encontro dos princípios de ecodesign.

O ecodesign é uma forma de projetar que considera os critérios ecológicos com tanta relevância quanto os demais requisitos projetuais. De acordo com a definição de Kazazian (2005, p. 36) o ecodesign é uma abordagem que reduz os impactos de um produto, conservando sua qualidade de uso, funcionalidade e desempenho para melhorar a qualidade de vida dos usuários. Assim, os aspectos ambientais são tratados com o mesmo status quanto a funcionalidade, durabilidade, custos, estética, ergonomia e qualidade (PIGOSSO et al., 2010).

Para Cândido (2011, p. 16) o ecodesign diz respeito ao "ato de projetar produtos com a preocupação focada no ambiente e em todo seu ciclo de vida, evitando ou diminuindo as agressões ao ecossistema". A introdução deste conceito como elemento de ordem na concepção de novos produtos trouxe aos projetistas a consciência de seu papel em uma grande cadeia de intervenções sobre o meio ambiente.

Neste sentido, Salado (2011, p. 100) e Preston e Bank (2012) comentam que os tubos de papelão promovem o uso de resíduos de papéis descartados, com conteúdo inerente de papel reciclado, e podem ser reutilizados por diversas vezes. Após estarem danificados, eles podem ser reciclados, gerando novos elementos idênticos. Além disso, o processo de fabricação destes tem baixo consumo energético e baixo impacto ambiental.

A cola utilizada no processo é vegetal, geralmente à base de fécula de milho, sendo renovável, biodegradável e sem substâncias tóxicas. Não há combinação de materiais, o que caracteriza o monomaterialismo. O principal material (papel $\mathrm{kraft}^{1}$ ) não passa pelo processo de branqueamento, reduzindo consideravelmente os resíduos tóxicos. Sobre este assunto, Petutschnigg e Ebner (2007, p. 408) observam que como o papel consiste principalmente em fibras de madeira e é um recurso renovável, pode ser um material interessante e sustentável para as futuras demandas, substituindo outros. Os mesmos autores também defendem que a aplicação de novos materiais é dependente principalmente das suas propriedades específicas, incentivando a análise e estudo destas características.

Para maximizar a utilização dos tubos, apresentando-o como um material ecológico e passível de aplicação no design, torna-se necessário que suas características e seus parâmetros técnicos sejam reconhecidos e difundidos. Desta forma, nesta pesquisa serão estudados os parâmetros de resistência à compressão axial e diametral deste material, visando sua aplicação em usos que requeiram esta característica.

\footnotetext{
${ }^{1}$ Papel resistente feito com celulose química virgem, a partir da mistura de fibras de celulose retiradas de polpas de madeiras macias. Podem ser naturais (sem branquear) ou branqueados (FOELKEL, 2013).
} 


\section{Materiais e métodos}

Os tubos de papelão utilizados nesta pesquisa foram adquiridos em uma fábrica localizada em Porto Alegre - RS. Possuem 76,2mm de diâmetro interno (3 polegadas), e são amplamente utilizados no setor gráfico (enrolamento de papéis e adesivos). Durante todo o período anterior aos ensaios, os tubos foram protegidos das influências que pudessem alterar suas propriedades, como a luz direta do sol, flutuações climáticas consideráveis, líquidos e umidade, conforme dita a norma.

Existem vários "modelos" de tubos, variando em sua espessura e comprimento; a medida padronizada é o diâmetro interno $76,2 \mathrm{~mm}$. A espessura varia de acordo com o material ao qual o tubo servia como suporte ao enrolamento, sendo que neste trabalho serão analisados quatro modelos: $3 \mathrm{~mm}, 4 \mathrm{~mm}, 5 \mathrm{~mm}$ e $6,5 \mathrm{~mm}$ de espessura. O detalhamento das características e quantidade de corpos de prova para cada ensaio é apresentado a seguir, no Quadro 1:

Quadro 1 - Descrição dos corpos de prova utilizados em cada ensaio.

\begin{tabular}{|c|c|c|}
\hline Ensaio & Características dos corpos de prova & Quantidade \\
\hline Resistência à compressão axial & $\begin{array}{l}\text { Cinco corpos de prova de cada espessura ( } 3 \mathrm{~mm}, 4 \mathrm{~mm}, 5 \mathrm{~mm} \text { e } \\
6,5 \mathrm{~mm} \text { ) de } 100 \mathrm{~mm} \text { de comprimento, de acordo com a ABNT NBR } \\
\text { ISO 11093-9:2009 - Papel e cartão - Ensaio de tubetes- Parte 9: } \\
\text { Determinação da resistência ao esmagamento, que determina } \\
\text { que corpos de prova cortados de tubetes com diâmetro interno } \\
\text { nominal menor ou igual a } 300 \mathrm{~mm} \text { devem ter comprimento de } \\
\text { 100mm, com tolerância de } 1,5 \mathrm{~mm} \text { (para mais ou para menos) em } \\
\text { todos os pontos. }\end{array}$ & 20 \\
\hline $\begin{array}{l}\text { Resistência à compressão } \\
\text { diametral }\end{array}$ & $\begin{array}{l}\text { Cinco corpos de prova de cada espessura, de } 100 \mathrm{~mm} \text { de } \\
\text { comprimento., de acordo com a ABNT NBR ISO 11093-9:2009 - } \\
\text { Papel e cartão - Ensaio de tubetes- Parte 9: Determinação da } \\
\text { resistência ao esmagamento. }\end{array}$ & 20 \\
\hline
\end{tabular}

Fonte: a autora.

Ressalta-se que, de todos os espécimes coletados, foram descartados $100 \mathrm{~mm}$ de cada uma das extremidades, em conformidade com as normas ABNT NBR ISO 11093-9:2009 - Papel e cartão - Ensaio de tubetes: Determinação da resistência ao esmagamento e ABNT NBR 14257:1998 Papel e cartão - Tubetes - Determinação da umidade - Método por secagem em estufa.

Somente depois de estabelecido o equilíbrio de umidade entre os corpos de prova e atmosfera (requerido para estabilizar o estado físico dos materiais) é que os materiais foram submetidos aos ensaios. Para isso, foram mantidos por um período de dez dias no Laboratório de Design e Seleção de Materiais da Universidade Federal do Rio Grande do Sul (LdSM/UFRGS), na atmosfera condicionadora de temperatura $23^{\circ} \mathrm{C}$ e umidade relativa $50 \%$, conforme ABNT NBR 14102:2002 Papel e cartão - Tubetes - Condicionamento das amostras, até que atingissem a massa constante.

Os corpos de prova foram cortados rigorosamente a 90ำ com relação ao seu eixo em uma serra circular de esquadria; equipada com disco de corte com lâmina de wídea de 32 dentes, sem causar deformações, e suas medidas foram aferidas com o uso de trena e paquímetro universal. A retirada das rebarbas da superfície cortada foi obtida pelo uso de lixas. 


\subsection{Resistência à compressão axial}

O objetivo do ensaio de compressão é comparar a resistência à compressão de vinte corpos de prova, de quatro espessuras distintas, de tubos de papelão secos e sem revestimento. Assim, pretende-se reconhecer o comportamento do material em aplicações onde a resistência é um requisito, de modo a assegurar boa precisão dimensional quando solicitado a esses esforços.

A compressão é um esforço axial aplicado de modo uniforme, com o sentido da força dirigido para o interior da peça, paralelamente à seção transversal do corpo de prova. Este ensaio foi guiado pela norma ABNT NBR ISO 11093-9:2009 - Papel e cartão - Ensaio de tubetes- Parte 9: Determinação da resistência ao esmagamento, que determina o comprimento de $100 \pm 1,5 \mathrm{~mm}$ em todos os pontos, para corpos de prova cortados de tubos com diâmetro interno nominal $\leq 300 \mathrm{~mm}$.

O equipamento utilizado é a máquina de ensaios universal, marca EMIC ${ }^{\circledR}$ (Figura 1), com uma célula de carga de $200 \mathrm{kN}$, onde os corpos de prova são posicionadas entre duas placas lisas (uma fixa e outra móvel) paralelas entre si e submetidos à força uniaxial. Os ensaios de compressão foram realizados no Núcleo Orientado para a Inovação da Edificação - NORIE/UFRGS.

Figura 1 - Máquina de ensaios universal localizada no NORIE/UFRGS

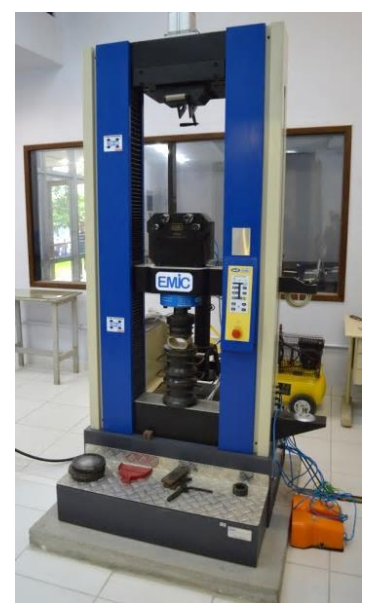

Fonte: a autora.

O procedimento da norma descreve que o corpo de prova deve estar centralizado entre as duas placas, de maneira que seu eixo longitudinal esteja perpendicular a elas; o esmagamento deve ser realizado movendo, de modo uniforme, uma placa na direção da outra com uma velocidade relativa constante entre 55 e $65 \mathrm{~mm} / \mathrm{min}$, submetendo o corpo de prova à carga até que o primeiro ponto máximo de resistência ao esmagamento seja notadamente ultrapassado.

\subsection{Resistência à compressão diametral}

Neste ensaio a força de compressão foi aplicada nos tubos posicionados paralelamente ao seu eixo. Utilizaram-se as diretrizes do ensaio anterior, guiando-se novamente pela ABNT NBR ISO 11093-9:2009 - Papel e cartão - Ensaio de tubetes: Determinação da resistência ao esmagamento. Também se realizou este ensaio no NORIE, na máquina de ensaios universal EMIC ${ }^{\circledR} 200 \mathrm{kN}$. 


\section{Resultados e discussão}

\subsection{Resistência à compressão axial}

Os corpos de prova foram posicionados entre as placas de pressão, de maneira que seu eixo longitudinal estivesse perpendicular às placas (Figura 2). Foram utilizados cinco corpos de prova de cada espessura estudada $(3,4,5$ e $6,5 \mathrm{~mm})$, com $100 \mathrm{~mm}$ de comprimento e uma massa média individual de 45,31g.

Figura 2 - Corpo de prova sendo submetido ao ensaio de compressão axial.

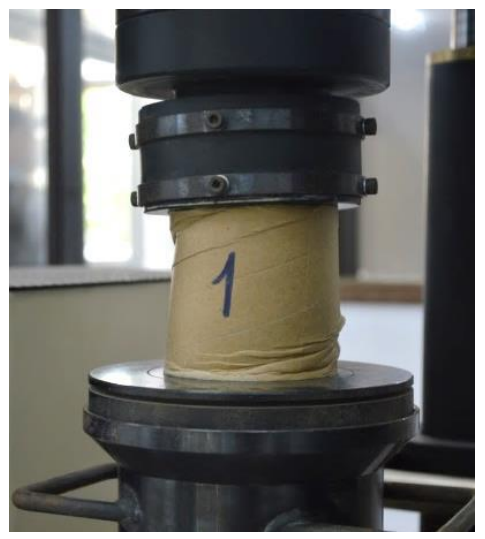

Fonte: a autora.

Através dos resultados, geraram-se gráficos onde são apresentados os valores de máxima força e tensão de cada um dos corpos de prova. Em todos os gráficos, padronizou-se o valor máximo de força em $12000 \mathrm{~N}$, para que fosse possível comparar as curvas geradas.

No gráfico a seguir (Figura 3) pode-se ver as curvas tensão $X$ deslocamento dos cinco corpo de provas de $3 \mathrm{~mm}$ de espessura. Percebe-se que o comportamento apresentado pelo grupo foi semelhante: a máxima força suportada ficou próxima à faixa dos $4000 \mathrm{~N}$, e o deslocamento máximo foi de cerca de $2,5 \mathrm{~mm}$, ocorrendo pouco amassamento.

Figura 3 - Resultados do ensaio de compressão axial - CPs 3mm espessura.

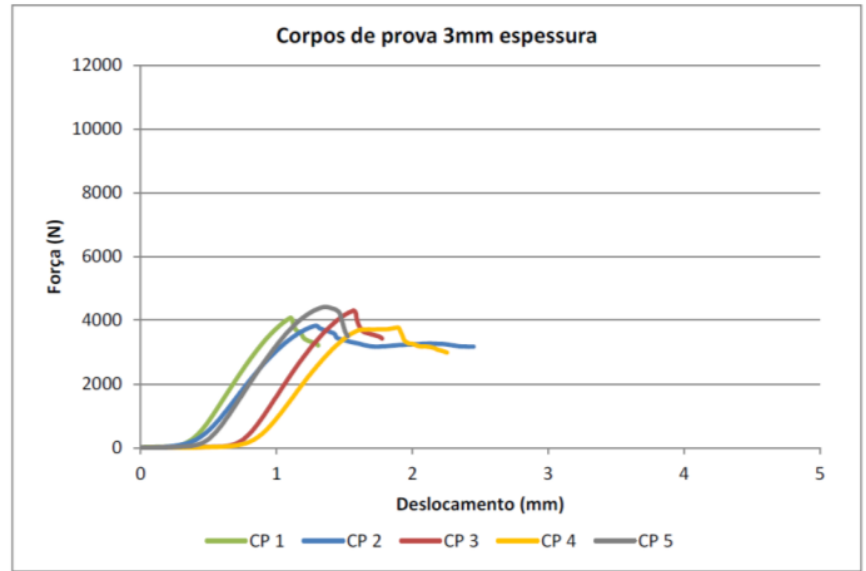

Fonte: a autora. 
A carga média suportada pelos tubos de espessura de parede $3 \mathrm{~mm}$ é $415,66 \mathrm{kgf}$, resultado satisfatório considerando-se a pouca espessura e leveza (cerca de 45,31g) dos corpos de prova. $\mathrm{Na}$ sequência, a Figura 4 compara a aparência dos corpos de prova antes (A) e após (B) o ensaio de compressão axial. Percebem-se apenas algumas ondulações no sentido de enrolamento das faixas de $k$ raft, sem amassamentos salientes.

Figura 4 - Comparação entre os corpos de prova 3mm de espessura. (A) Antes do ensaio; (B) Após o ensaio de compressão axial.

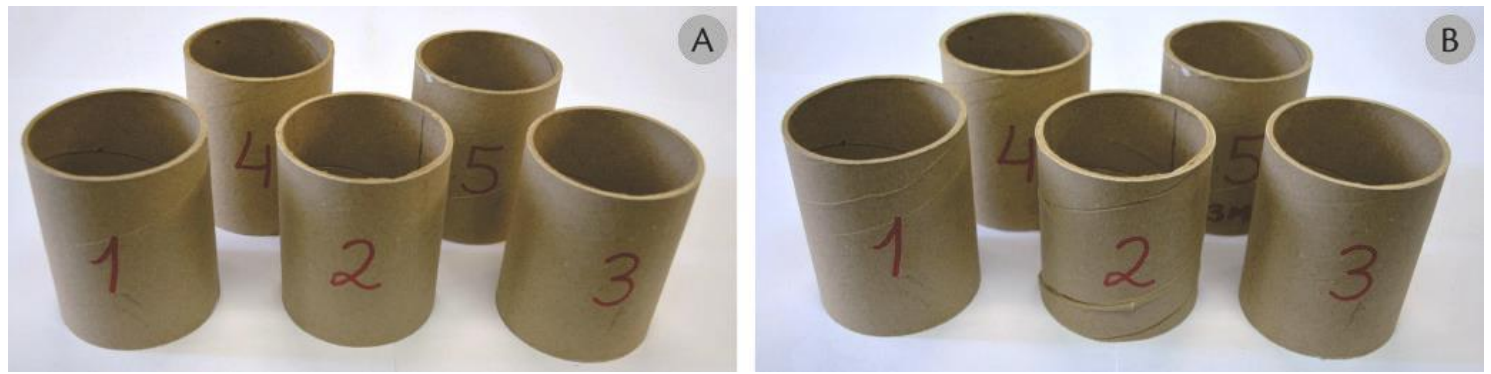

Fonte: a autora.

O segundo ensaio foi realizado com o grupo de corpos de prova de $4 \mathrm{~mm}$ de espessura de parede, e massa média de 66,46g. A visualização das curvas do gráfico (Figura 5) comprova que os corpos de prova também tiveram um comportamento similar, com pouca variação na força máxima suportada, que ficou na faixa dos $5000 \mathrm{~N}$.

Em relação ao deslocamento, neste grupo ele foi mais evidente: com exceção do corpo de prova número 4 , que rompeu com $2 \mathrm{~mm}$ de compressão, os outros corpos de prova deformaram entre 10 e $20 \mathrm{~mm}$ até a interrupção da força de compressão.

Figura 5 - Resultados do ensaio de compressão axial - CPs $4 \mathrm{~mm}$ espessura.

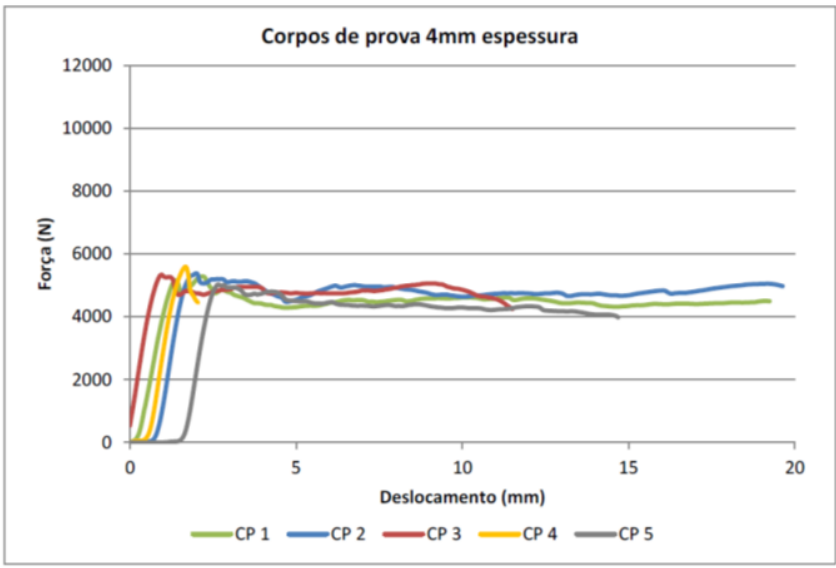

Fonte: a autora.

A carga média máxima suportada foi 550,33 kgf, 134,67 kgf a mais do que a média das cargas máximas dos corpos de prova de $3 \mathrm{~mm}$ de espessura. Nestes tubos, a deformação ocorrida foi mais visível que nos anteriores: podem-se ver amassamentos, aumento da espessura da borda, 
ondulações e relevos no interior e exterior dos corpos de prova (Figura 6).

Figura 6 - Comparação entre os corpos de prova 4mm de espessura. (A) Antes do ensaio; (B) Após o ensaio de compressão axial.

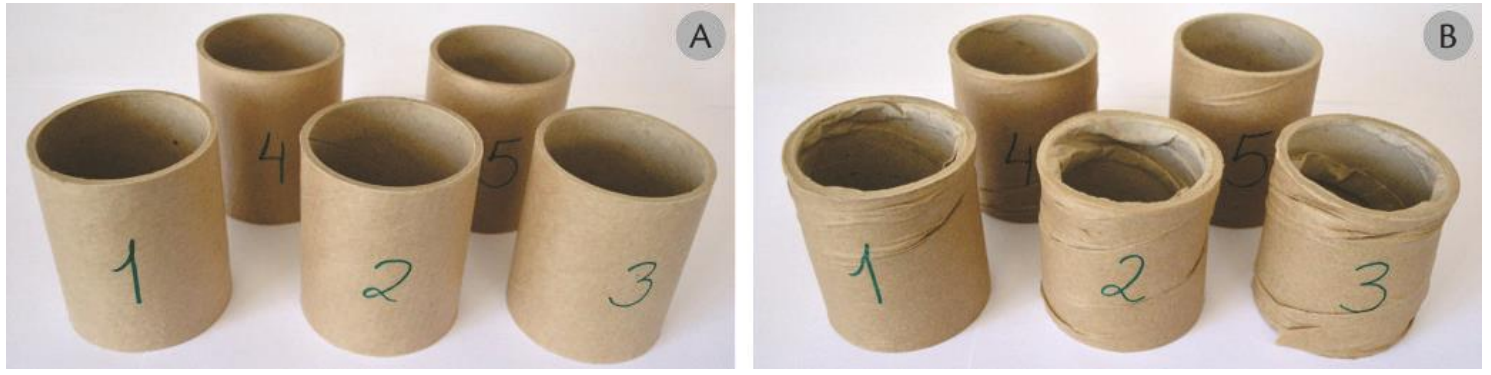

Fonte: a autora.

Na sequência, realizaram-se os ensaios de compressão com os corpos de prova de $5 \mathrm{~mm}$ de espessura de parede e massa média de $88,63 \mathrm{~g}$. O ponto máximo de força foi semelhante em todo o grupo, em uma média de $8500 \mathrm{~N}$. O deslocamento também mostrou um padrão, com exceção do CP 2, que apresentou ruptura com $1,95 \mathrm{~mm}$.

As curvas força versus deslocamento (Figura 7) apresentam uma sequência nítida de perda e ganho de resistência: percebe-se uma queda na força suportada, que após alguns milímetros de deformação volta a aumentar. Concluiu-se que a perda acontecia devido aos espaços e falhas entre as emendas das faixas de kraft; quando esta emenda era amassada formando uma ondulação, consequentemente os CPs voltavam a ganhar resistência e suportar mais força.

Figura 7 - Resultados do ensaio de compressão axial - CPs $5 \mathrm{~mm}$ espessura.

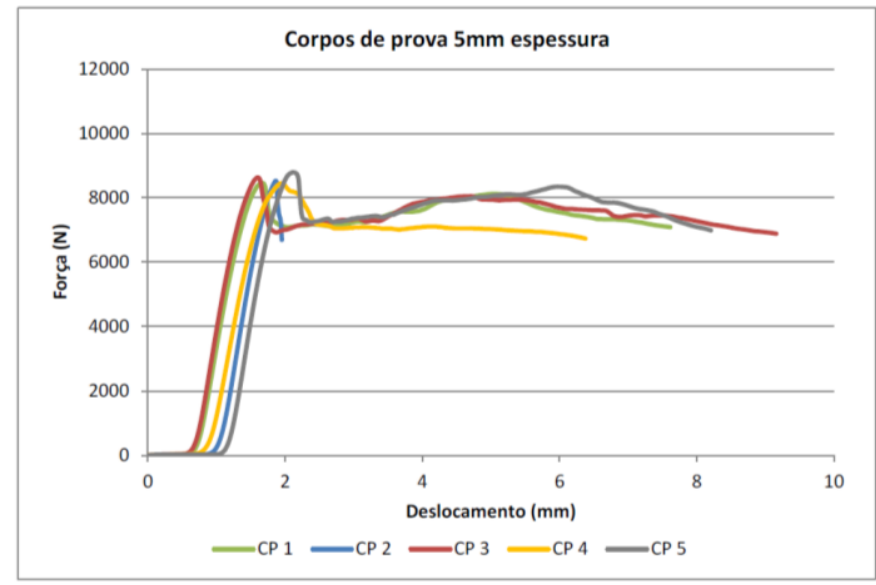

Fonte: a autora.

A máxima carga média suportada foi quase $874 \mathrm{kgf}, 323,6 \mathrm{kgf}$ a mais que os tubos de $4 \mathrm{~mm}$ de espessura e $458,27 \mathrm{kgf}$ superior à máxima carga média suportada pelos tubos de $3 \mathrm{~mm}$ de espessura. A relação massa $X$ carga mostra que são suportados quase $10 \mathrm{kgf}$ por grama.

Pela observação visual e tátil dos corpos de prova após a compressão (Figura 8) nota-se que o CP 2 não apresentou a mesma deformação que os outros corpos de prova, que tiveram ondulações 
nas superfícies interna e externa, amassamento e aumento da espessura das bordas em contato com as placas de pressão; sua ruptura foi mais rápida, sem regiões amassadas nem aumento da espessura das bordas, devido à existência de falhas entre as emendas de papel kraft.

Figura 8 - Comparação entre os corpos de prova de $5 \mathrm{~mm}$ espessura. (A) Antes do ensaio; (B) Após o ensaio de compressão axial.
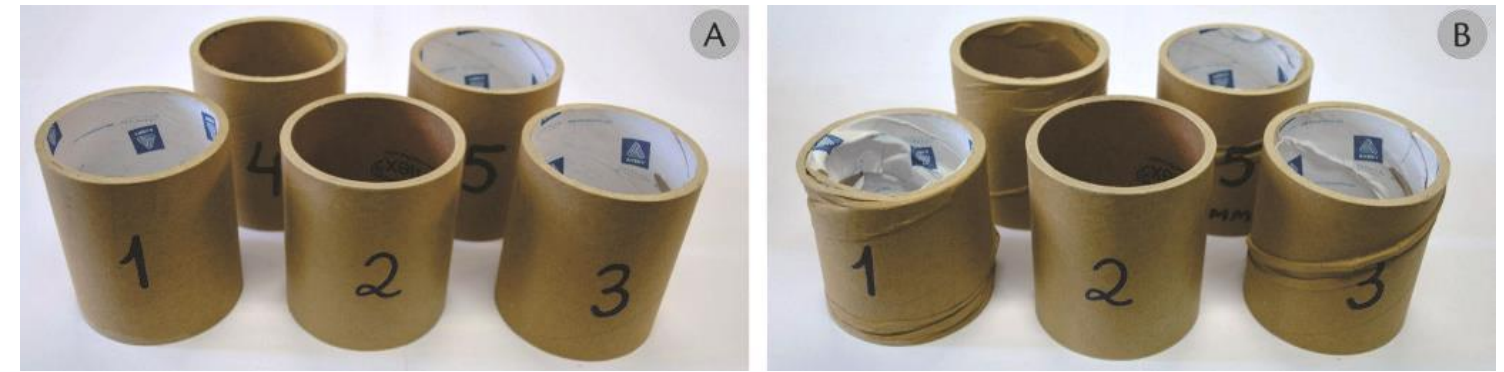

Fonte: a autora.

O último grupo de corpos de prova a ser ensaiado foi o de $6,5 \mathrm{~mm}$ de espessura de parede, de massa média de 120,96g. Este grupo foi o que apresentou resultados mais heterogêneos de máxima força, com valores variando entre $9432,1 \mathrm{~N}$ e $12979 \mathrm{~N}$, porém com semelhança em relação ao deslocamento. Da mesma forma que o grupo de $5 \mathrm{~mm}$ de espessura, este também teve uma sequência de perda e aumento da resistência, demonstrada por todos os CPs (Figura 9).

Figura 9 - Resultados do ensaio de compressão axial - CPs 6,5mm espessura.

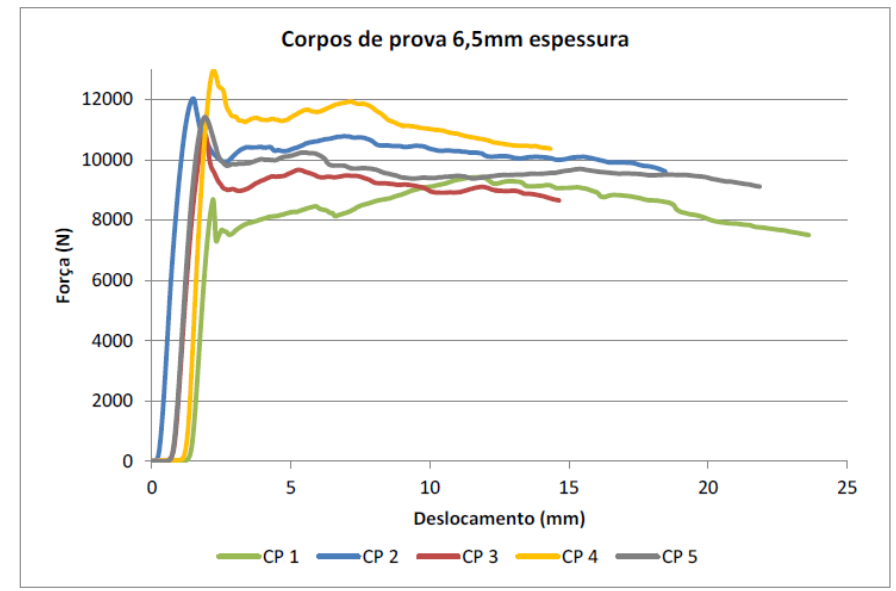

Fonte: a autora.

A média da força máxima suportada foi $11109,66 \mathrm{~N}$, ultrapassando uma tonelada de carga $(1132,87 \mathrm{kgf})$. Comparando-se com os resultados apresentados pelos grupos anteriores, houve um acréscimo de $717,21 \mathrm{kgf}$ em relação aos tubos de $3 \mathrm{~mm}$ de espessura, $582,54 \mathrm{kgf}$ a mais que os corpos de prova de $4 \mathrm{~mm}$ e $258,94 \mathrm{kgf}$ superior ao grupo de $5 \mathrm{~mm}$ de espessura. Nas imagens comparativas abaixo (Figura 10) pode-se visualizar que estes foram os corpos de prova que apresentaram mais deformação. 
Figura 10 - Comparação entre os corpos de prova de 6,5mm espessura. (A) Antes do ensaio; (B) Após o ensaio de compressão axial.

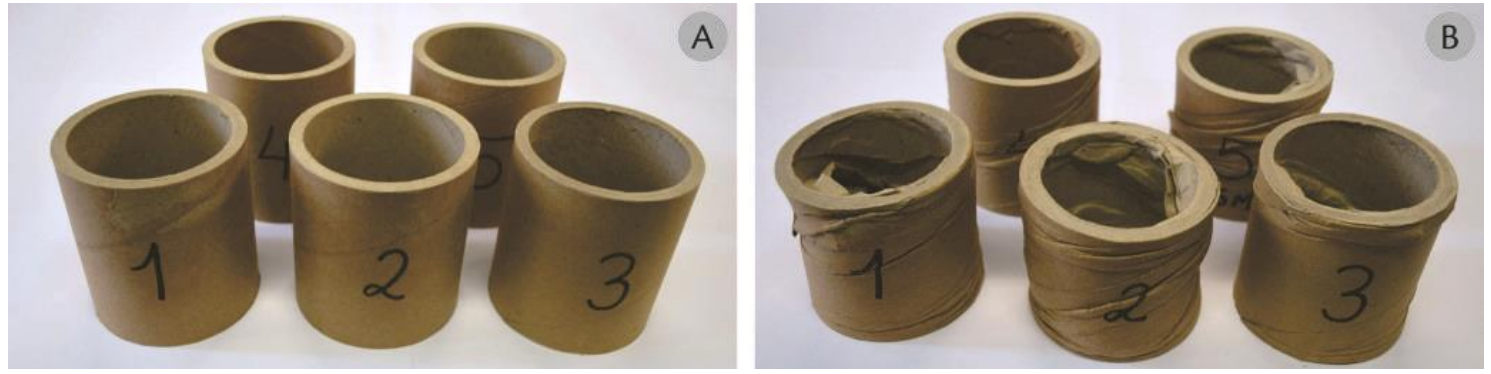

Fonte: a autora.

Pela observação visual e tátil dos corpos de prova das quatro espessuras após o ensaio, podese perceber que apresentaram esmagamento das bordas, em alguns casos com aumento de espessura; também surgiram ondulações tanto na face externa quanto na interna, causando deformações com dobras bastante aparentes, no sentido de enrolamento das faixas de papel kraft (especificamente nas emendas). Algumas vezes, apesar de não evidentes na face externa, as deformações eram visíveis na superfície interna dos tubos (Figura 11).

Figura 11 - Deformações nos corpos de prova após os ensaios de compressão axial. (A) Ondulações e dobras na superfície interna, na emenda de papel kraft; (B) Amassamento na superfície externa; (C) Dobra saliente na face externa, no sentido de enrolamento das faixas; (D) Esmagamento da borda superior, com aumento da espessura da borda, e ondulações nas superfícies interna e externa.
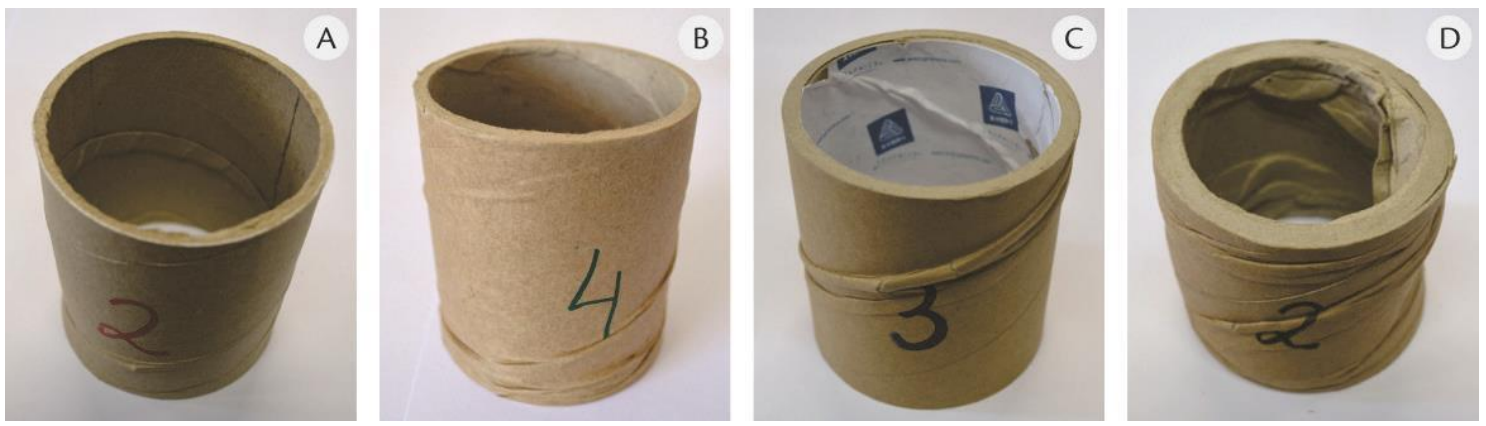

Fonte: a autora.

Pelos resultados do ensaio de compressão axial, chegou-se a uma lista de fatores que podem influenciar na resistência dos tubos de papelão: espessura da parede, já que os tubos mais espessos suportaram uma força de compressão maior; existência de falhas entre as emendas de papel kraft; tipo e eficiência da cola utilizada; e a qualidade e gramatura do papel.

Este fator é confirmado por Cardoso et al. (2012) no estudo sobre papéis reciclados utilizados para a fabricação de tubetes: conforme os autores, os melhores resultados de resistências físicas e mecânicas foram atribuídas ao papel com menor porcentual de fibra reciclada, devido à maior rigidez, maior número de ligações entre as fibras e maior força entre essas ligações, formando um papel com melhor conformabilidade da rede fibrosa. 


\subsection{Resistência à compressão diametral}

Neste ensaio, os corpos de prova foram posicionados entre as placas de pressão, de maneira que seu eixo longitudinal estivesse paralelo às placas (Figura 12). Foram utilizados cinco corpos de prova de cada espessura estudada, totalizando novamente 20 corpos de prova.

Figura 12 - Corpo de prova sendo submetido ao ensaio de compressão diametral.

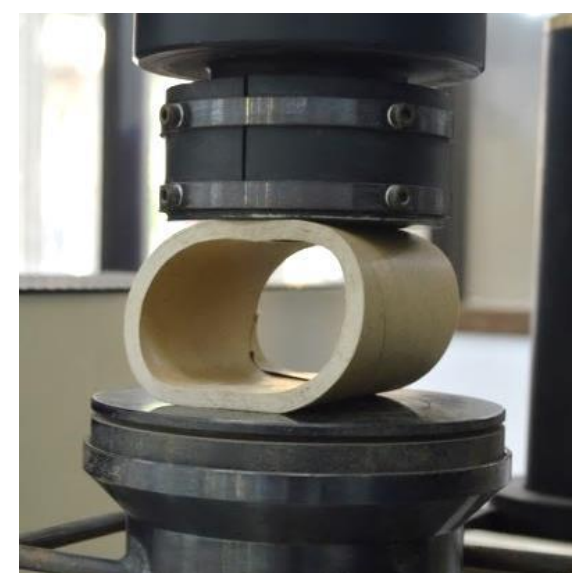

Fonte: a autora.

Padronizou-se o valor máximo de força nos gráficos em $800 \mathrm{~N}$, para que fosse possível comparar as curvas geradas. No gráfico a seguir (Figura 13) pode-se ver as curvas tensão $X$ deslocamento dos cinco corpo de provas de $3 \mathrm{~mm}$ de espessura. O comportamento do grupo de CPs durante a compressão diametral apresentou um padrão bem definido: a máxima força suportada ficou próxima aos $200 \mathrm{~N}$, e o deslocamento máximo foi cerca de $12 \mathrm{~mm}$.

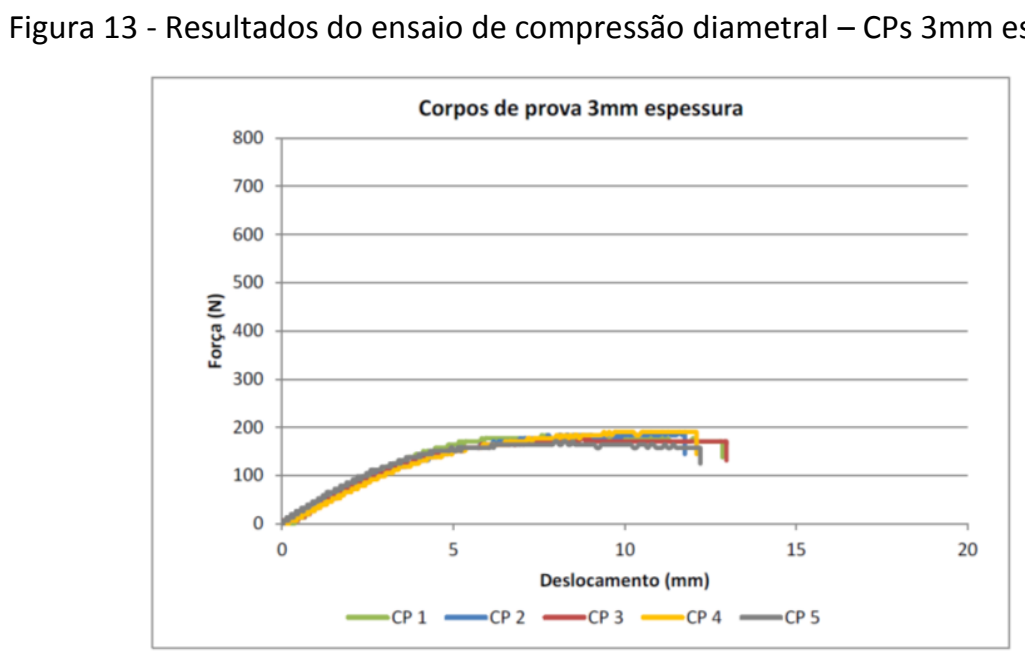

Fonte: a autora.

A carga média suportada pelos tubos de espessura de parede $3 \mathrm{~mm}$ é $18,58 \mathrm{kgf}$, valor consideravelmente menor que a média carga máxima suportada no ensaio de compressão axial, que foi $415,66 \mathrm{kgf}$. 
O segundo ensaio foi realizado com o grupo de corpos de prova de $4 \mathrm{~mm}$ de espessura de parede. A visualização das curvas do gráfico (Figura 14) comprova que os CPs também tiveram um comportamento similar, com pouca variação na força máxima suportada, que ficou na faixa dos $250 \mathrm{~N}$.

Figura 14 - Resultados do ensaio de compressão diametral - CPs 4mm espessura.

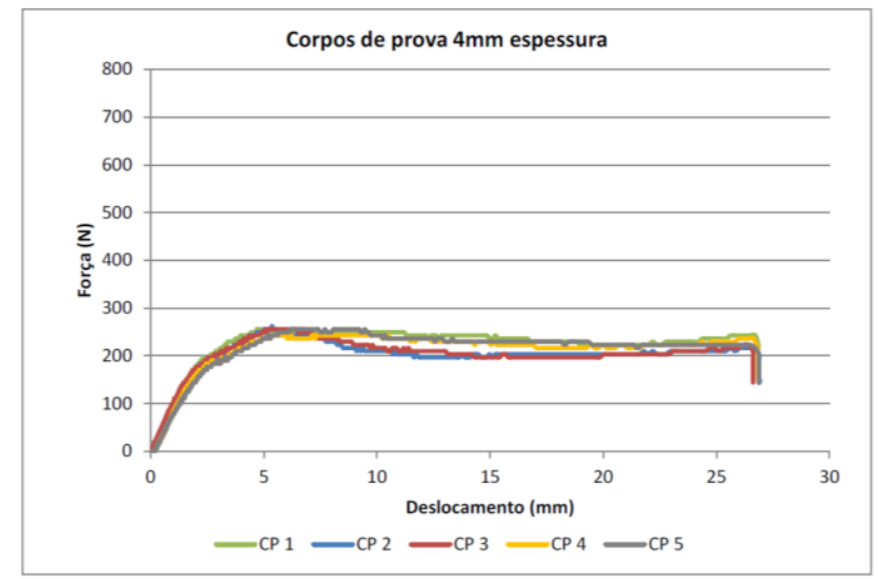

Fonte: a autora.

Comparando os resultados com o ensaio anterior do grupo de $3 \mathrm{~mm}$, percebe-se um acréscimo de 7,13kgf na máxima carga média suportada. Em contraponto ao ensaio de compressão axial, os tubos de $4 \mathrm{~mm}$ de espessura apresentaram uma diferença de 524,62kgf para menos no sentido diametral de compressão.

Continuando, realizaram-se os ensaios com os corpos de prova de $5 \mathrm{~mm}$ de espessura de parede. Neste grupo, notaram-se comportamentos distintos em cada corpo de prova em relação à força máxima, que variou entre $387 \mathrm{~N}$ e $512 \mathrm{~N}$. Já a deformação máxima apresentou um padrão, com o valor médio de $17 \mathrm{~mm}$ de deslocamento (Figura 15).

Figura 15 - Resultados do ensaio de compressão diametral - CPs $5 \mathrm{~mm}$ espessura.

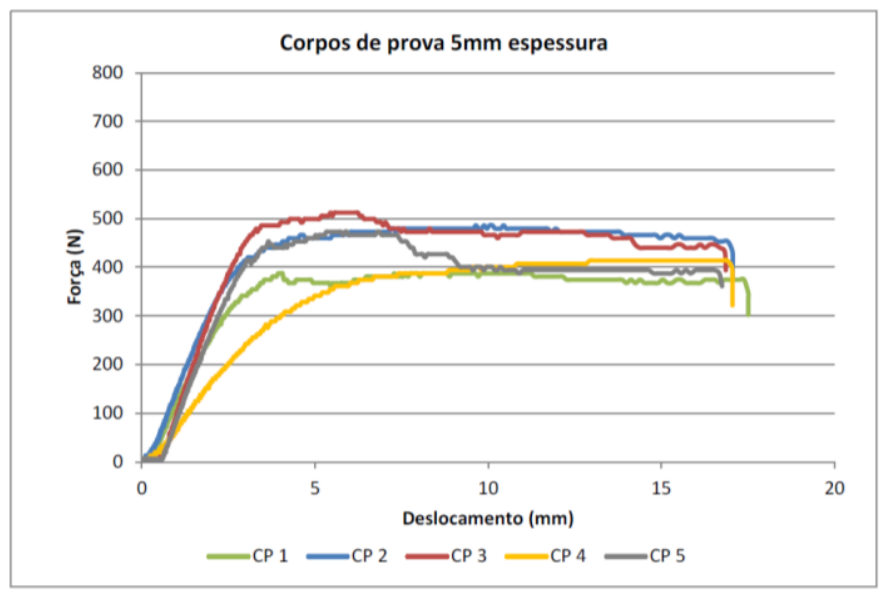

Fonte: a autora. 
Fazendo um comparativo com os resultados apresentados pelos corpos de prova de $5 \mathrm{~mm}$ de espessura com os corpos de prova de $3 \mathrm{~mm}$ e $4 \mathrm{~mm}$, ressalta-se um aumento de respectivamente, 27,76kgf e 20,63kgf na máxima carga média suportada. Já em relação ao valor de máxima carga média exposta pelos tubos de $5 \mathrm{~mm}$ no sentido axial de compressão, calculou-se uma diferença de $827,59 \mathrm{kgf}$ de diminuição de resistência no sentido diametral. A relação massa $X$ carga, que na compressão axial com os tubos de espessura $5 \mathrm{~mm}$ resultou em quase $10 \mathrm{kgf}$ por grama, neste apresenta apenas 0,5kgf/grama.

O último ensaio de compressão realizado foi com os corpos de prova de $6,5 \mathrm{~mm}$ de espessura de parede. Este grupo apresentou resultados heterogêneos de máximo deslocamento, mas semelhantes em relação à máxima força, conforme se visualiza pelas curvas de força $X$ deformação na Figura 16.

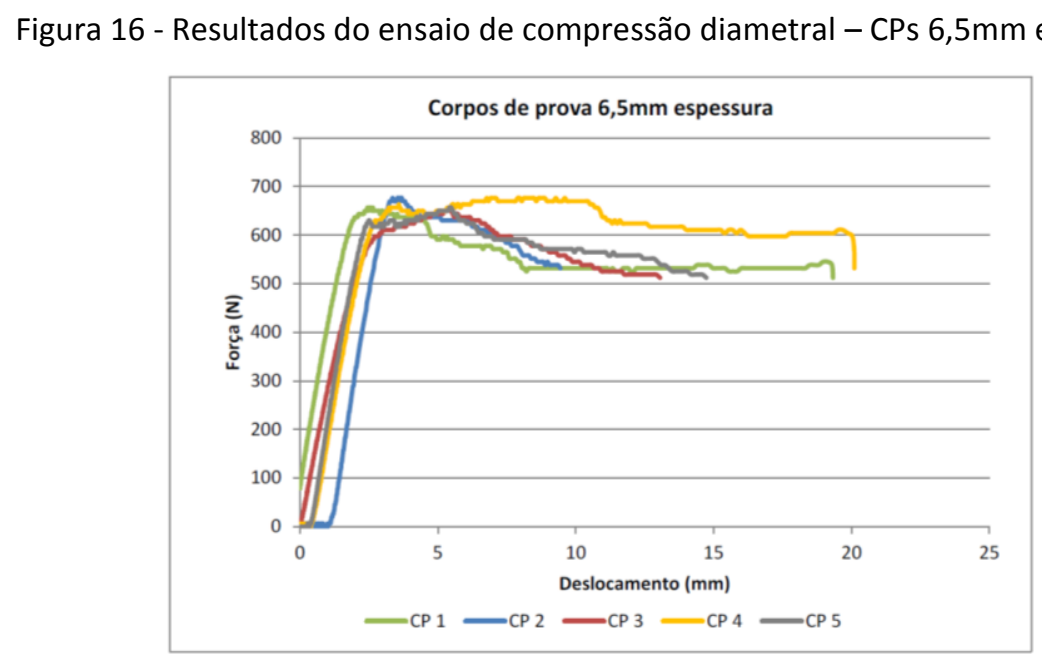

Fonte: a autora.

A máxima carga de $67,64 \mathrm{kgf}$ suportada pelos tubos de $6,5 \mathrm{~mm}$ de espessura foi $21,3 \mathrm{kgf}$ superior àquela apresentada pelos CPs de $5 \mathrm{~mm}$ de espessura, 41,93kgf aos de $4 \mathrm{~mm}$ e 49,06kgf aos de $3 \mathrm{~mm}$ de espessura no sentido de compressão diametral. Mesmo assim, o valor ainda é muito inferior ao de máxima carga média suportada no sentido de compressão axial, que foi de $1132,87 \mathrm{kgf}$ no grupo de 6,5mm de espessura - ou seja, uma diferença de 1065,23kgf.

Através da observação visual e tátil dos corpos de prova após o ensaio, pode-se perceber que as deformações não foram tão drásticas quanto no ensaio anterior, de compressão axial. Apenas houve um esmagamento na seção transversal, causando uma distorção na forma inicialmente circular, e após, elíptica (Figura 17). Porém, não foram percebidas ondulações, amassamentos ou aumento da espessura das bordas. 
Figura 17 - À esquerda, corpo de prova após o ensaio de compressão diametral; à direita, corpo de prova não submetido ao ensaio.

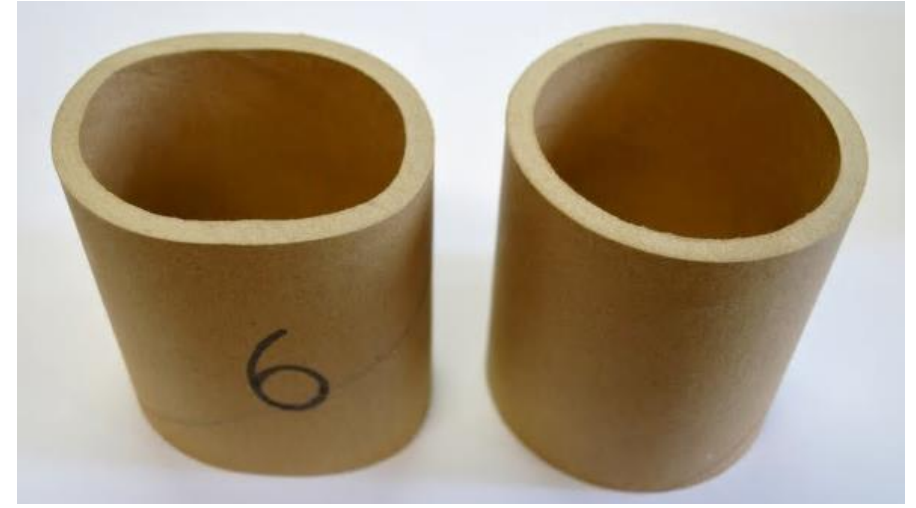

Fonte: a autora.

Realizando-se uma comparação entre os dois tipos de ensaios de compressão realizados axial e diametral - evidencia-se que a resistência vertical dos tubos é maior que a horizontal: no grupo de corpos de prova de $3 \mathrm{~mm}$ de espessura de parede, a diferença entre os valores de máxima carga média dos ensaios foi 22 vezes (415,66 e 18,58kgf) maior na compressão axial; no de $4 \mathrm{~mm}$ de espessura, 21 vezes (550,33 e 25,71 kgf); no grupo de corpos de prova de $5 \mathrm{~mm}$ de espessura de parede, 19 vezes (873,93 e 46,34kgf); e, finalmente, no grupo de 6,5mm a diferença foi de 17 vezes maior na carga máxima média suportada no sentido axial de compressão $(1132,87$ e $67,64 \mathrm{kgf})$.

Para facilitar o entendimento e comparação direta dos dados, as tabelas a seguir mostram detalhadamente os valores referentes à massa (em gramas), força $(\mathrm{N})$, carga (kgf) e deslocamento (mm) de cada grupo de corpos de prova com a mesma espessura. A Tabela 1 refere-se aos resultados do ensaio de compressão axial, e a Tabela 2 aos do ensaio de compressão diametral.

Tabela 1 - Comparação dos resultados do ensaio de compressão axial com as médias de cada espessura.

\begin{tabular}{l|l|l|l|l}
\hline Corpo de prova & $\mathbf{3 m m}$ & $\mathbf{4 m m}$ & $\mathbf{5 m m}$ & $\mathbf{6 , 5} \mathbf{m m}$ \\
\hline Massa média (g) & 45,31 & 66,46 & 88,63 & 120,96 \\
\hline Máxima força média (N) & 4076,3 & 5396,92 & 8570,36 & 11109,66 \\
\hline Máxima carga média (kgf) & 415,66 & 550,33 & 873,93 & 1132,87 \\
\hline Máximo deslocamento médio (mm) & 1,86 & 13,42 & 6,66 & 18,58 \\
\hline
\end{tabular}

Fonte: a autora.

Tabela 2 - Comparação dos resultados do ensaio de compressão diametral com as médias de cada espessura.

\begin{tabular}{l|l|l|l|l}
\hline Corpo de prova & $\mathbf{3 m m}$ & $\mathbf{4 m m}$ & $\mathbf{5 m m}$ & $\mathbf{6 , 5} \mathbf{m m}$ \\
\hline Massa média (g) & 46,02 & 66,55 & 87,83 & 122,55 \\
\hline Máxima força média (N) & 182,60 & 252,22 & 454,53 & 663,40 \\
\hline Máxima carga média (kgf) & 18,58 & 25,71 & 46,34 & 67,64 \\
\hline Máximo deslocamento médio (mm) & 12,37 & 26,81 & 17,04 & 15,33 \\
\hline
\end{tabular}

Fonte: a autora.

Apesar do resultado satisfatório apresentado pelos corpos de prova de $6,5 \mathrm{~mm}$ de 
espessura na compressão diametral (se comparado aos tubos de outras espessuras), acredita-se que a direção mais adequada e com maior relevância de utilização dos tubos de papelão é a vertical, com o sentido da carga aplicado paralelamente à seção transversal.

\section{Conclusão}

Com a realização dos ensaios de compressão identificou-se a superioridade da resistência dos tubos com a força sendo aplicada no sentido axial, perpendicularmente ao seu eixo longitudinal. A carga média suportada nos ensaios de compressão axial foi cerca de 19 vezes maior que nos ensaios de compressão diametral, nos tubos de todas as espessuras estudadas, e foi considerada suficiente para viabilizar a utilização dos tubos no design de produtos de uso pessoal.

A seguir (Figura 18), apresentam-se brevemente produtos nacionais confeccionados com tubos de papelão, de forma a expor algumas das possibilidades de aplicações no design de produtos em usos em que a resistência é um requisito imprescindível.

Figura 18 - Produtos confeccionados com tubos de papelão. À esquerda: banquinho Biju, do SuperLimão Studio. No centro, estante Anéis, de Nido Campolongo; à direita, módulo Mobina, da autora.
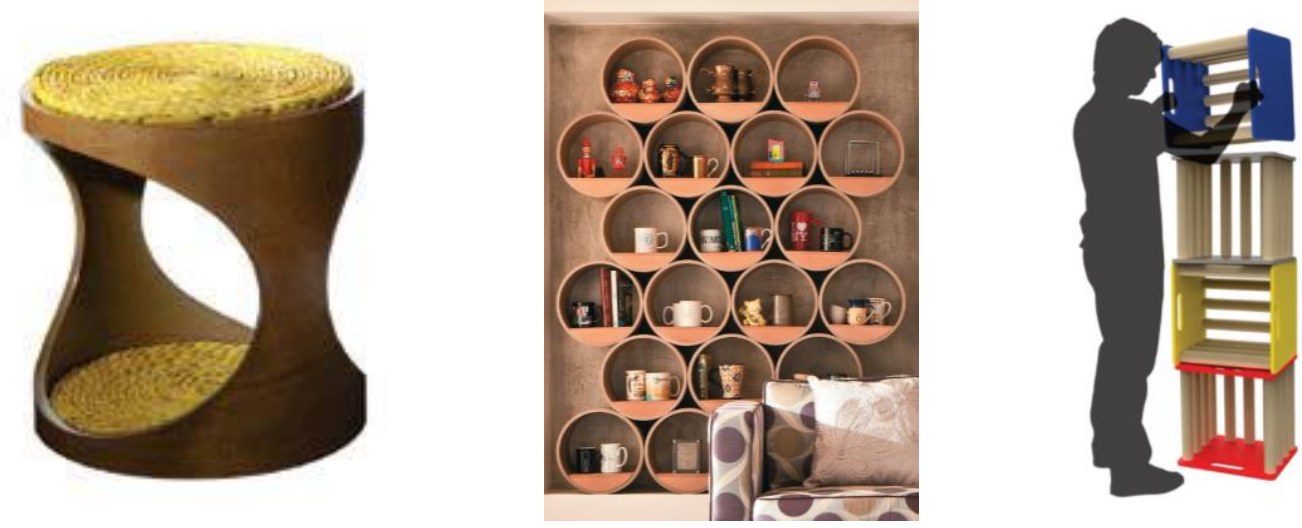

Fonte: SuperLimão (2018), Nido Campolongo (2018), da autora.

Em relação aos experimentos, apesar de os tubos de papelão terem apresentado um resultado superior no ensaio de compressão axial, não se rejeita a possibilidade de serem utilizados no sentido diametral, desde que seja feita durante o projeto uma boa análise estrutural.

A falha sofrida no ensaio de compressão axial é estável (não repentina) e progressiva, aumentando de acordo com o aumento da força de compressão. Estas características são positivas para a aplicação dos tubos em produtos que dependam de boa resistência.

Por fim, se reconhece que cada modelo de tubo (variação de espessura e diâmetro) tem potencial para ser aplicado em algum tipo de produto, adequando suas propriedades aos requisitos do que está sendo projetado. Com os tubos de papelão, pode-se obter alto desempenho para algumas funções específicas; contudo, é importante que a vida dos materiais esteja ajustada ao tempo de vida do produto.

O estudo e reconhecimento de características peculiares de novos materiais é um ponto determinante para a inserção destes no design. Aspectos culturais relegam o papelão a uma 
função secundária, como embalagem, por exemplo, e não como matéria prima na fabricação de produtos. Mas essa concepção está mudando, na medida em que se encontram referências, se projetam produtos e, principalmente, se descobrem as características deste material.

\section{Referências}

ASSOCIAÇÃO BRASILEIRA DE NORMAS TÉCNICAS. NBR 14101: papel e cartão: tubetes: amostragem para ensaios. Rio de Janeiro, 1998.

ASSOCIAÇÃO BRASILEIRA DE NORMAS TÉCNICAS. NBR 14257: papel e cartão: tubetes: determinação da umidade: método por secagem em estufa. Rio de Janeiro, 1998.

ASSOCIAÇÃO BRASILEIRA DE NORMAS TÉCNICAS. NBR 14484: papel e cartão: tubetes: medição das dimensões. Rio de Janeiro, 2000.

ASSOCIAÇÃO BRASILEIRA DE NORMAS TÉCNICAS. NBR ISO 11093-9: papel e cartão: ensaio de tubetes: parte 9: determinação da resistência ao esmagamento. Rio de Janeiro, 2009.

CÂNDIDO, Luis Henrique Alves. Contribuição ao estudo da reutilização, redução e da reciclagem dos materiais com aplicação do ecodesign. 2008, 126p. Dissertação - Programa de Pós Graduação em Engenharia de Minas, Metalúrgica e de Materiais - Escola de Engenharia, Universidade Federal do Rio Grande do Sul, Porto Alegre, 2008.

CARDOSO, Maro Túlio; CARNEIRO, Angélica de Cássia Oliveira; OLIVEIRA, Rubens Chaves de; CARVALHO, Ana Márcia Macedo Ladeira; PATRÍCIO JÚNIOR, Wagner; MARTINS, Maria Cristina; SANTOS, Rosimeire Cavalcanti dos; SILVA; Juliana Cristina da. Propriedades físicas e mecânicas de papéis reciclados utilizados para fabricação de tubetes. In: Ciência Florestal Santa Maria, v 22, n 2, abr-jun 2012, p. 403-411.

FOELKEL, Celso. Pinnusletter. Disponível em: <http://www.celsofoelkel.com.br/pinusletter.>. Acesso em: jul. 2012.

KAZAZIAN, Thierry (organiz.) Haverá a idade das coisas leves: design e desenvolvimento sustentável. 2. ed. Tradução de Eric Roland Rene Heneault. São Paulo: Senac, 2005.

NIDO CAMPOLONGO. 2012. Design no cenário sustentável. Disponível em: http://www.nidocampolongo.com.br/. Acesso em: 05 abril 2018.

PETUTSCHNIGG, Alexander Johannes; EBNER, Michael. Lightweight paper materials for furniture - a design study to develop and evaluate materials and joints. In: Materials \& Design, n 28, 2007, p. 408-413.

PIGOSSO, Daniela C.A; ZANETTE, Evelyn T; GUELERE FILHO, Américo; OMETTO, Aldo R.; ROZENFELD, Henrique. Ecodesign methods focused on remanufacturing. In: Journal of Cleaner Production, n 18, 2010, p. 21-31.

PRESTON, Steven J.; BANK, Lawrence C. Portals to an Architecture: Design of a temporary structure with paper tubes. In: Construction and Building Materials, n 30, 2012, p. 657-666.

SALADO, Gerusa de Cássia. Painel de vedação vertical de tubos de papelão: estudo, proposta e análise de desempenho. 2011, 290p. Tese - Programa de Pós-Graduação em Arquitetura e Urbanismo, Escola de Engenharia de São Carlos, Universidade de São Paulo, São Paulo, 2011 